
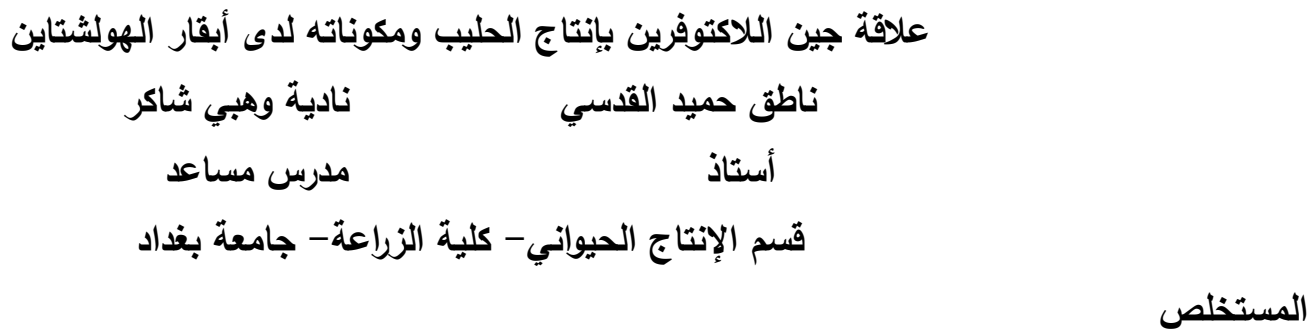

نفذ البحث في حقل الأبقار التابع لقسم الإتتاج الحيواني ومختبر التقانات الإحيائية والفسلجة الحيوية في كلية الزراعة/ جامعة بغداد

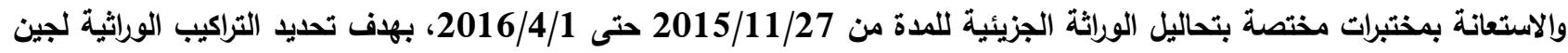

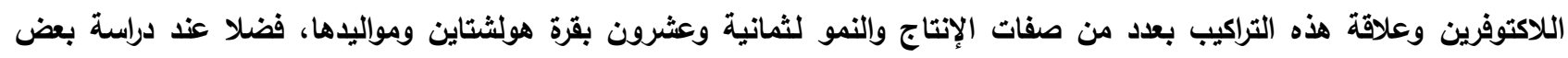

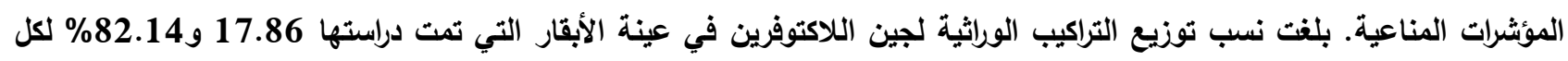
من التراكيب الوراثية AA وABA بالتتابع، وكان التباين بين هاتين النسبتين عالي المعنوية. كان التكرار الاليلي للأليل A Aو هو

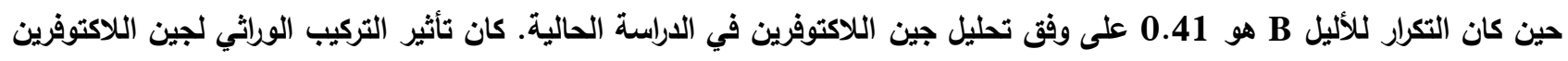

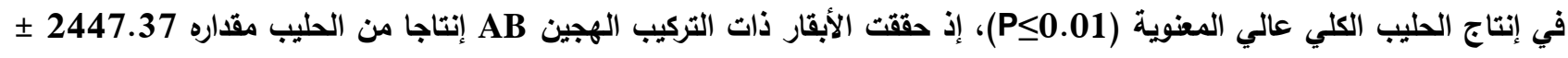

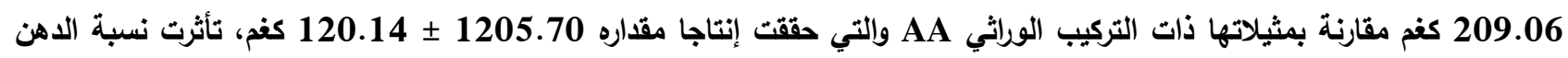

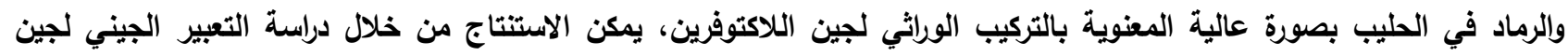

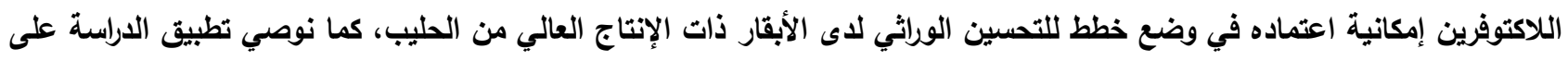

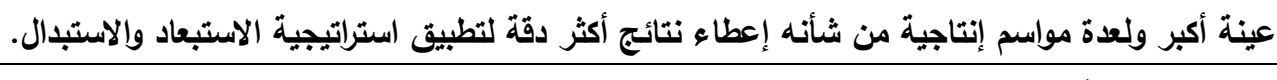
مستل من رسالة الماجستير للباحث الثاني الكلمات المفتاح: جين اللاكتوفرين، إنتاج الحليب، أبقار الهولثتاين.

The Iraqi Journal of Agricultural Sciences- 48(1): 375-381,2017

Alkudsi \& Shaker

\title{
THE RELATIONSHIP OF LACTOFERRIN GENE WITH MILK PRODUCTION AND ITS COMPONENT IN HOLSTEIN COW
}

\author{
N. H. Alkudsi \\ N.W. Shaker \\ Prof. \\ Assist Lecturer
}

\section{ABSTRACT}

Dep. of Animal Production / College of Agriculture / Univ. of Baghdad

This resesrch was conducted at the Dairy Cattle Farm pertaining to the Department of Animal Production, College of Agriculture in Abu-Ghraib (20 km West of Baghdad) and Al-Jaderiah, as well as at the Biotechnology Physiology Laboratory at the College of Agriculture, University of Baghdad, Al-Jaderiah, and in collaboration with the Laboratory that specific for molecular genetic analysis during the period from $27 / 11 / 2015$ to $1 / 04 / 2016$. The objective of this study was to identify the polymorphism of lactoferrin gene and their relationship with some growth and productive traits for 28 Holstein cows and their borns, along with the study of some immunological indicators. The distribution percentages of lactoferrin gene polymorphism in cow's sample were 17.86 and $82.14 \%$ for $A A$ and $A B$ respectively. The variation between these percentages were highly significant $(P \leq 0.01)$. The allele frequency for $A$ and $B$ were 0.59 and 0.41 respectively, according to the lactoferrin gene analysis carried out currently. The effect of lactoferrin gene polymorphism on milk yield was highly significant $(\mathrm{P} \leq 0.01)$, being cows with $\mathrm{AB}$ yielded $2447.37 \pm 209.06 \mathrm{~kg}$, while those with AA yielded $1205.70 \pm 120.14 \mathrm{~kg}$. The lactation period has not significantly affected by lactoferrin gene polymorphism. The influence of lactoferrin gene polymorphism was obvious on milk fat $(\mathrm{P} \leq 0.01)$ and ash $(\mathrm{P} \leq \mathbf{0 . 0 5})$ percentages, while other milk components (lactose, protein and solid non-fat) did not. It can be concluded from the study of gene expression for lactoferrin gene, the possibility of adopted them in cattle breeding strategy,. We also recommend to apply the study on a larger sample and for several productive lactions that will give more accurate results from the application of culling and replacement strategies.

Key words: Lactoferrin Gene , milk production, Holstein cow 
وتحديد التركيب الوراثي لكل حيوان وقراءة تسلسل القواعد

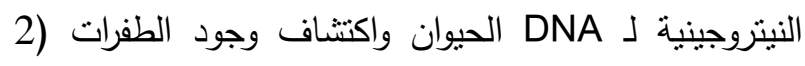
و10). ويمكن الاستفادة من هذه التقنيات في تحليل الواسمات الجزيئية وهي ذات أهمية كبيرة لاسيما عند تقييم السلالات ( 9) أذ أن تضمين معلومات مواقع الصفة الكمية (QTL - Quantitative Trait Loci) يوفر إمكانات كبيرة في زيادة دقة الانتخاب وزيادة العائد الانتخابي في برامج التحسين الوراثي (18 ) ) ، وأفاد أيضا

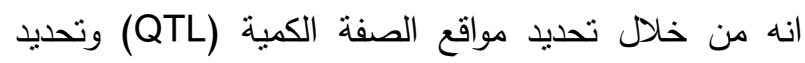
الواسمات المرتبطة بها يمكن التتبؤ بالتباين المظهري للصفات

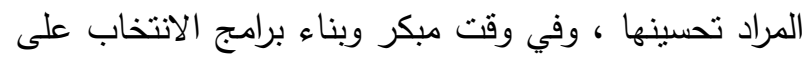

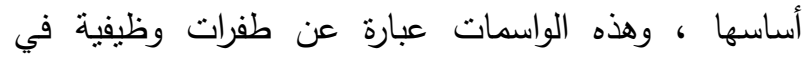
الجينات المؤثرة في الصفات ومن أقدم الواسمات الوراثية التي استخدمت في برامج التربية هي الواسمات الثكلية (Morphological Markers) الكروموسومية ثم الواسمات الكيمياحيوية وأخيرا الواسمات الوراثية (Genetic Markers) التي تعتمد على المادة

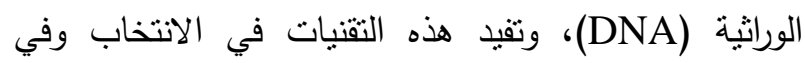

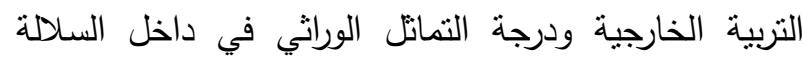
ودراسة الارتباطات بين الجينات الاقتصادية ذات الثكل

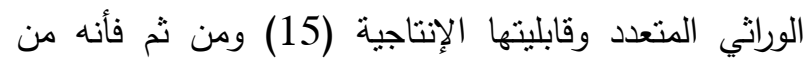
المكن استخدام هذه الواسمات الجزيئية (13 و و14) في الإسيه الانتخاب والتحسين. ونظر لأهمية بروتين اللاكتوفرين في الدئ الجهاز المناعي الذاتي في سوائل الجسم ومنها الحليب جاءت برته فكرة الدراسة للبحث في الجين المؤثز في تركيز هذه المادة

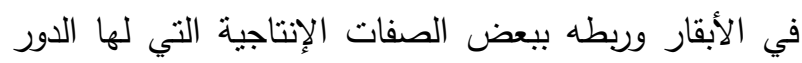

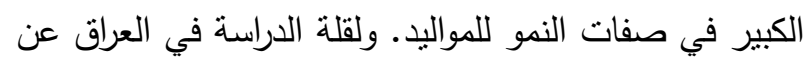

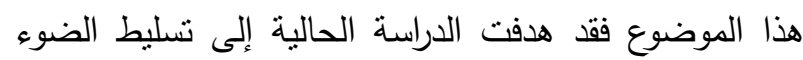

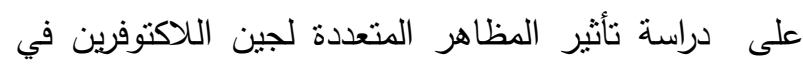

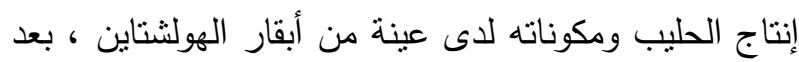
استخراج نسب نوزيع تلك المظاهر والتكرار الاليلي.

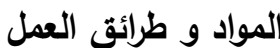

أجريت التجربة على مجموعة من أبقار الهولثتاين فريزيان

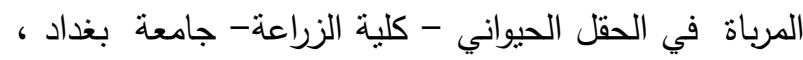

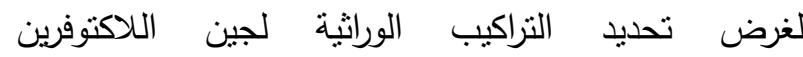
والتوصيف الجزيئي لمعرفة Lactoferrin gene (Lf )
المقدمة

يعتبر الحليب من المصادر الغذائية الضرورية للجسم

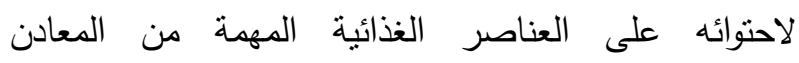
والفيتامينات التي تفي بطلب المستهلك الذي يسعى للحصول

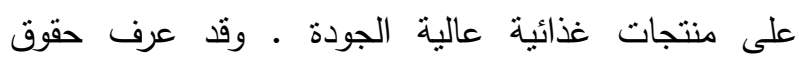
استهلاك الحليب في فرنسا عام 1909" الحليب على انه أنتاج متكامل من حليب منواصل لأنتى صحتها جيدة وبدون انقطاع وليس اكثر من طاقتها ولا يتضمن مرحلة أنتاج اللبأ

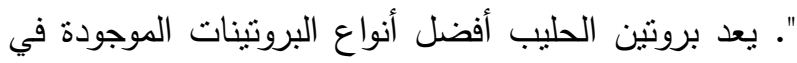

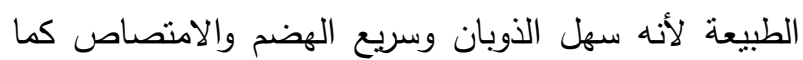
انه بحتوي على جميع الأحماض الأمينية الضرورية

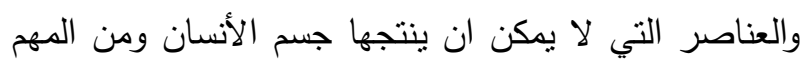

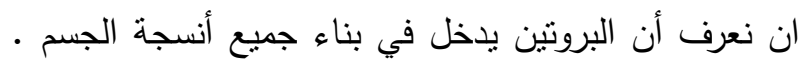

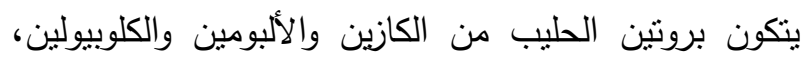
ويعتبر اللاكتوفرين (Lf) (Lactoferrin) من البروتينات المهمة وجزء من كلوبينات المناعة، كما ويعد جزء من نظام المناعة الطبيعي الذي يتوزع بصورة عامة خلال سوائل الجسم

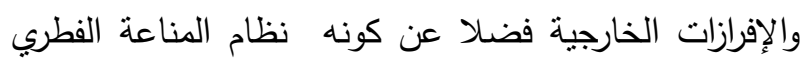
الأول (خط الدفاع لحماية الجسم من المسبيات الخارجية معززا الحماية ضد الأمراض المعدية والالتهابات حيث ينتج من الخلايا الحبيية العدلة (الخلايا البيضاء). تظهر اليهر المستويات العالية من اللاكتوفرين في اللبأ والحليب (11 و6) ويتم التحكم في كمية اللاكتوفرين المصنع في الغدة اللبنية

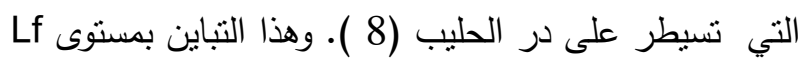
في الحليب خلال مرحلة الإدرار يقودنا إلى معرفة أين يكون مستواه اعلى من خلال تحليل التراكيب الوراثية للجين ولإنشاء قطعان ذات إنتاجية عالية بمستوى المناعة ومواليد بصحة

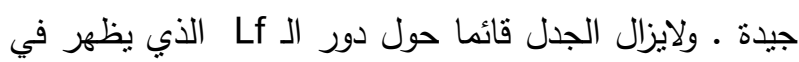
الية دفاع المضيف ضد المسبيات المرضية ومن خلال أيض دول الحديد. ان عمليات التحسين الوراثي قد حققت مكاسب كبيرة عن طريق دراسة التراكيب الوراثية لهذه الحيوانات وذللك من خلال دراسة الجينات التي تؤثر على الإنتاج ومعرفة الطفرات الوراثية وربطها بالتركيب المظهري باستخدام نقانة PCR

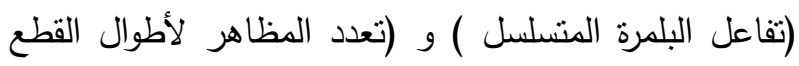
مestriction Fragment Length ) (RFLP مقيدة الطول (Polymorphism 
الجت و والذرة الصفراء واحيانا البرسيم ، إذ يقدم العلف راء الاخضر بالكمية والنوعية المتوافرة أو العلف الخشن الجاف المتمثل بالدريس ومادة التبن وعلى وجبتين صباحية ومسائية، كما يقدم العلف المركز بكمية تتراوح بحدود 2 كغم/ حيوان في الوجبة وترفع هذه الكمية قبل الموسم التتاسلي وفي اثنائه لتصل الى 3 كغم ا حيوان في الوجبة الواحدة للابقار الوالدة
التعدد المظهري للجين وعلاقته بإنتاج الحليب ومكوناته الرئيسة . أجريت التحاليل في مختبرات الدراسات العليا في كلية الزراعة - مختبر التقنيات الأحيائية والفسلجة ألحيوية جامعة بغداد ومختبر جسر المسيب في الجادرية على عينات الدم للمدة من 27 /11 /2015 ولغاية 4/1 / 2016. تربى الابقار في الحقل في حظائر نصف مفتوحة ، تتباين التغذية باختلاف الموسم وتبعا لتوافر الاعلاف الخضراء واهمها جدول 1: المواد الكميائية المستعملة

\begin{tabular}{|c|c|c|}
\hline الشركة المصنعة و المنشأ & 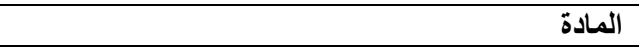 & $ت$ \\
\hline BIO BASIC & Agarose اكاروز & 1 \\
\hline AFCO (Jordan) & انابيب مانع التخثر EDTA مختلفة الأحجام & 2 \\
\hline BIO BASIC & 10X TBE Buffer Solution محول بفر منظم & 3 \\
\hline Bioneer(Korea) & DNA ladder Marker معلمات الحجم & 4 \\
\hline Bioneer(Korea) & صبغة برومو فينول الزرقاء Bromophenol Blue & 5 \\
\hline Promega (USA) & بوادئ Primers $\quad$ Pبئ & 6 \\
\hline Promega (USA) & extraction DNA kit عدة استخلاص الدنا & 7 \\
\hline Pioneer (korea) & عدة تفاعل البلمرة المتسلسل & 8 \\
\hline BIO BASIC & صبغة بروميد الاثيديوم Ethidium Bromide stain & 9 \\
\hline Pionee-Korea & الانزيم القاطع (EcoR1) & 10 \\
\hline
\end{tabular}

تحميل الـ DNA والترحيل الكهريائي

بعد تحميل العينات في الحفر الموجودة في الجل بواسطة تم سحب عينات الدم من الأبقار بمقدار 10-15 مل دم من الأنابيب الثعرية (Micropipette) وغمر الجل بمحلول الوريد الوداجي من كل بقرة في الحقل الحيواني وتقريغها في 1X TBE (Gel Electrophoresis ) فولت وبتيار مقداره 40 ملي أمبير ولمدة ساعة. ثم حمل طبقة الجل المتكونة بعد انتهاء المدة المقررة بأداة خاصة إلى جV Light) ال مطياف الأشعة فوق البنفسجية (Transillminator المتحركة من القطب السالب باتجاه القطب الموجب DNA بوساطة العين، ثم تصور هذه الحزم فوق جهاز المطياف

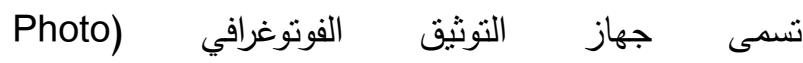
Documentation System بصبغة بروميد الاثيديوم (Ethidium Bromide) بلون برتقالي أو وردي متألق مما بدل على وجود DN. أنابيب مانع التخثر EDTA حجم 10 مل ، إذ جمعت العينات بثلاث وجبات كل وجبة في يوم حسب توزيع الأبقار في الحظائر • تم تقسيم كل عينة من الدم إلى قسمين في أنبوبنتين معلمة برقم كل بقرة، رتم حفظ الدم في الأنابيب بدرجة حـرارة - 20 م لعدة أيام لحين استخدامها.

التحليل الجزيئي لجين اللاكتوفرين ( Lf)

لغرض إجراء التحليل الجزيئي للجين Lf ) Lactoferrin على عينات الدم التي حفظت بالتجميد، وتمت التحاليل على ثلاث مراحل هي: المرحلة الأولى: استخلاص الحامض النووي الدنا DNA Extraction مل المرحلة الثانية: استخلاص القطعة المطلوبة Target من جين الاكتوفرين وتضخيمها (منتج الدنا DNA Product). المرحلة الثالثة : تقطيع القطعة المطلوبة لتحديد التراكيب الوراثية.

الامريكية

\begin{tabular}{|c|c|c|}
\hline اسم الجين ومختصره & & 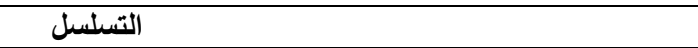 \\
\hline \multirow{2}{*}{ Lf gene } & & F: 5' - GCCTCATGACAACTCCCACAC -3' \\
\hline & Exon 17 & R : 5' - CAGGTTGACACATGGGTTGAC -3' \\
\hline
\end{tabular}


عينة الـ DNA الممزوجة مع 2 مايكروليتز من صبغة التحميل في حفر هلام الاكاروز تركيز 1\% وضبط الفولتية والتيار والزمن وتصوير ناتج الترحيل للتأكد من نجاح عملية استخلاص DNA كما في الثكل (1). تم استخلاص تناتج القطعة المطلوبة 301bp من جين اللاكتوفرين وتكثيرها (تضخيمها ) بتقانة بلمرة التفاعل التسلسلي (PCR) للحصول على منتج الـDNA Product) DNA) باستخدام

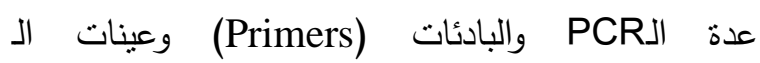
المستخلصة وضبط جهاز الدورات الحرارية حسب ما واتبات مذكور في فصل مواد وطرائق العمل ، ثم بعد ذللك تم ترحيل

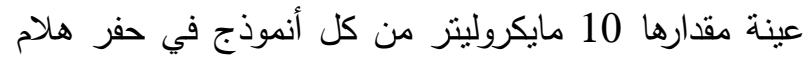

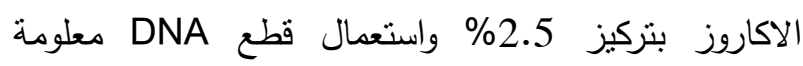

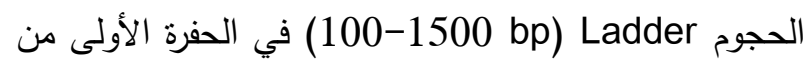
الجل بالمحلول المنظ 1x TBE وضبط الفولتية والتيار والزمن وتصوير ناتج الترحيل للتأكد من نجاح عملية

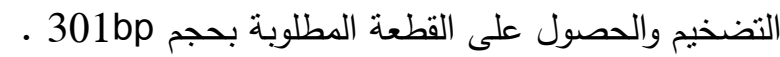
استخدام تقانة RFLP بأنزيم التقييا EcoR1 لتحديد التراكيب الوراثية

حددت التراكيب الوراثية لحيوانات التجربة لجين اللاكتوفرين بتطبيق تقانة RFLP وأنزيم التقييد EcoR1 وحسب الطريقة المذكورة في مواد وطرائق العمل وترحيل 10 مايكروليتز في وني هلام الاكاروز تركيز 2.5 \% وضبط الفولتية على 70

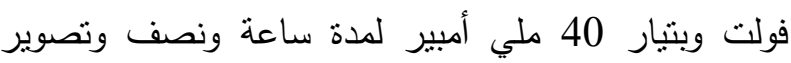
ناتج الترحيل للتعرف على توزيع التراكيب الوراثية للحيوانات المدروسة حسب عدد وحجم الحزم المتكونة، إذ تم استخدام

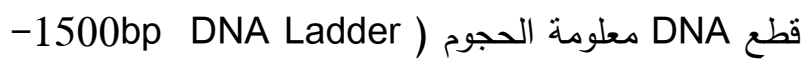
100) في الحفرة الأولى من الجل، وكما تظهر الحزم كما

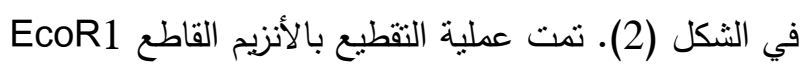

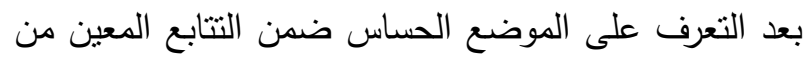
موقع القطع من قطعة الجين، لذا تشكلت من عملية التقطيع

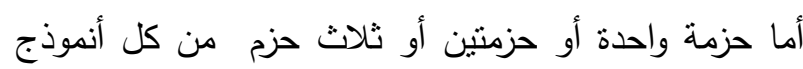

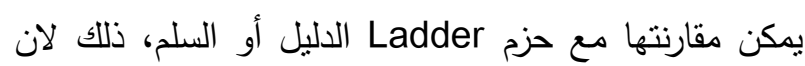
الأنزيم القاطع يقوم بعمله (التقطيع) في موقع تتابع الزوج حزي

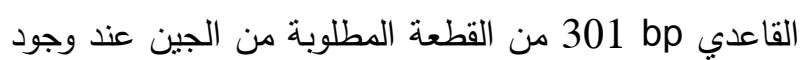

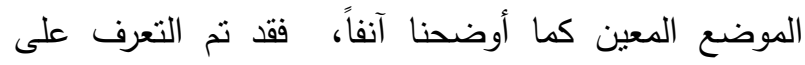

تحميل ناتج تفاعل البلمرة المتسلسل والترحيل الكهربائي عن طريق أنزيم القطع EcoR1(Restriction Enzyme) بعد انتهاء تفاعل البلمرة التسلسلي نم التعرف على التراكيب

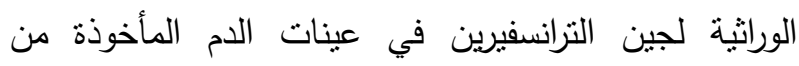

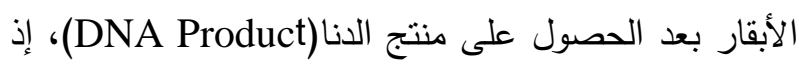

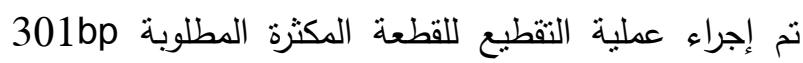
بالأنزيم المحدد (EcoRl) الذي يقوم بالتعرف على موضع

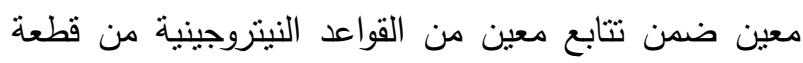

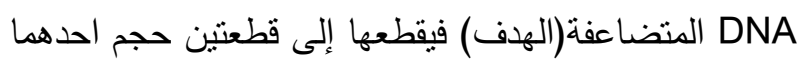

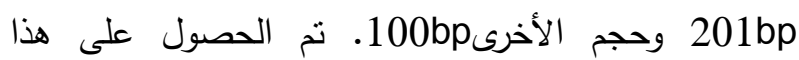
الأنزيم القاطع من شركة PIONEER الكورية بتركيز 20000 وحده لكل مول. التحليل الإحصائي

Statistical تم تحليل البيانات إحصائيا باستعمال البرنامج SAS- Analysis System المظاهر الوراثية لجين اللاكتوفرين في صفات إنتاج الحليب ومكوناته ، وقورنت المتوسطات الحسابية حسب اختبار (8 )

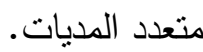
الأنموذج الرياضيـ: للتحري عن علاقة تعدد المظاهر الوراثية لجين اللاكتوفرين في انتاج الحليب وتركيب الحليب. $Y_{i j k l}=\mu+G_{i}+P_{j}+S_{k}+e_{i j k l}$

النتائج وإلمناقشة استخلاص الدنا DNA Extraction

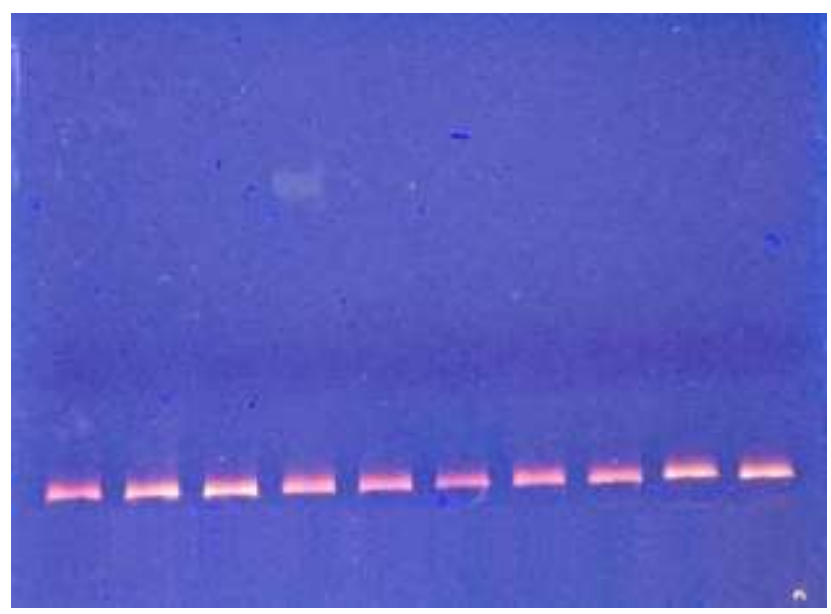

شكل 1 :استخلاص الـDNA

تم استخلاص الـ DNA كخطوة أولى لعزل القطعة الهدف لجين اللاكتوفرين بعد ذلك ضمن نقانة PCR وباستعمال العدة (Kit) وطريقة العمل المشار اليها في مواد وطرائق

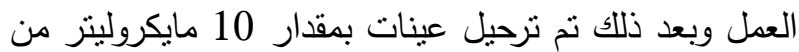


Sharifzadeh,A.andA.Doosti

(3) Zielak-Steciwko الهولشتاين الإيرانية ومع دراسة على أبقار الهولنتاين فريزيان الهولندية.

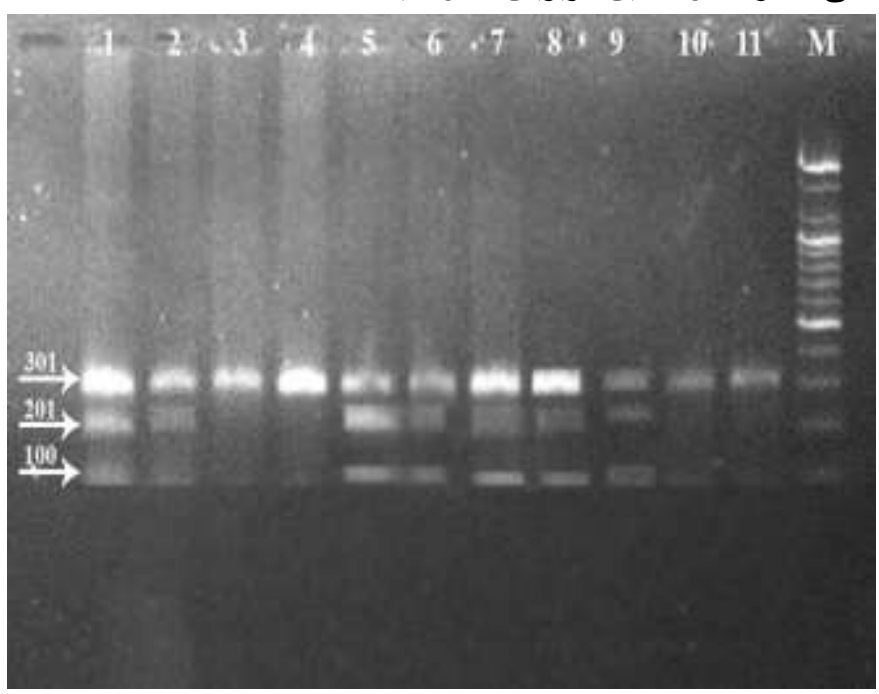

شكل 2 ـ الحزم المتكونة بعد عملية تقطيع أنزيم التقيبا

EcoR1

يتبين من الجدول 3 العدد والنسب المئوية للتراكيب الوراثية لجين

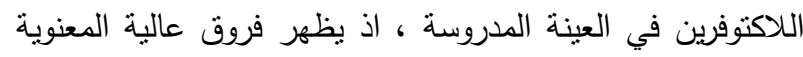

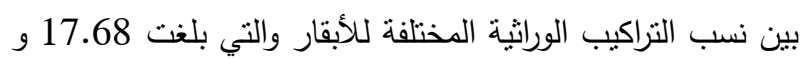

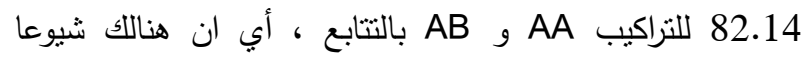
واضحا للأفراد الهجينة ( AB) مع تدني نسبة التركيب الوراثي

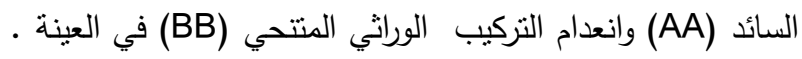

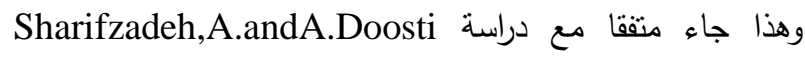
Zielak- على أبقار الهولثتاين الإبرانية ومع دراسة Steciwko

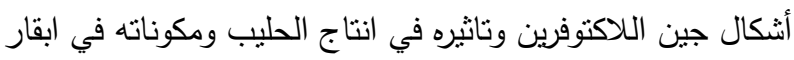

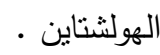

جدول 3 ـ العدد والنسب المئوية للمظاهر الوراثية لجين اللاكتوفرين في أبقار (Polymorphism) الهولثتاين قيد الاراسة

\begin{tabular}{|c|c|c|}
\hline النسبة المئوية(\%) & 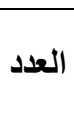 & $\begin{array}{c}\text { المظهر الوراثي } \\
\text { (Polymorphism) }\end{array}$ \\
\hline 17.86 & 5 & $\mathbf{A A}$ \\
\hline 82.14 & 23 & $\mathbf{A B}$ \\
\hline$\% 100$ & 28 & المجموع \\
\hline$* * 11.5714$ & -- & 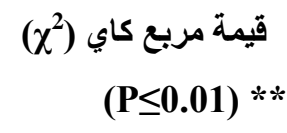 \\
\hline
\end{tabular}

التراكيب الوراثية (Genotype) لجين اللاكتوفرين في العينات المدروسة بهذه الطريقة وكما يلي: 1- إذا حصل الثقيع بالأنزيم القاطع في المكان السابق تتابع الزوج القاعدي 100bp في كلا الثريطين من القطعة فسوف تتكون قطعتين من كل شريط تظهر كحمنين، حجم

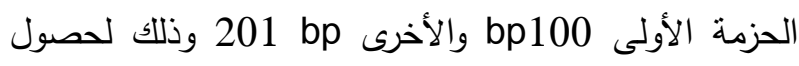
تذاخل كل حزمنين من الحجم نفسه من كلا الثريطين

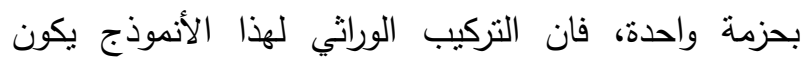
متماثلا (Homozygous) وهو يمنل التركيب الوراثي البري لئي (BB) Wild 2-إذا حصل التقطيع في احد الثريطين دون الثريط الأخر

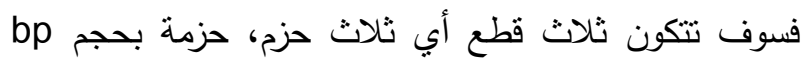

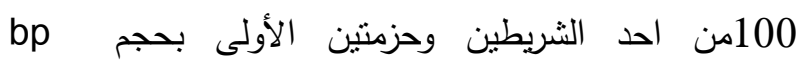

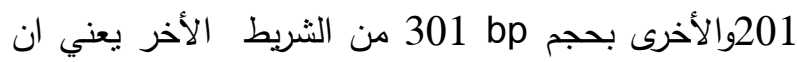

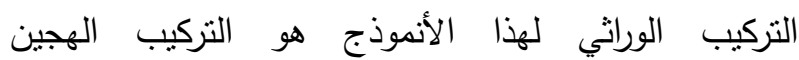

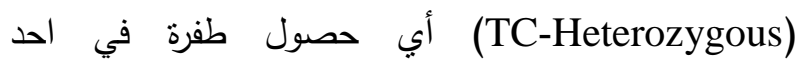
الثربطين أي تغير القاعدة A إلى القاعدة B في شريط دون

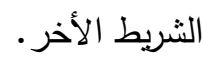
3- إذا لم يحصل التقطيع في كلا الثريطين فسوف تتكون حزمة واحدة بحجم 301 bp وذلك لتداخل الحزمتين معا

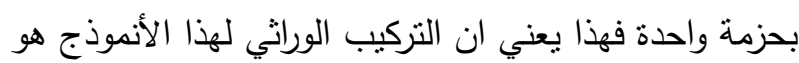

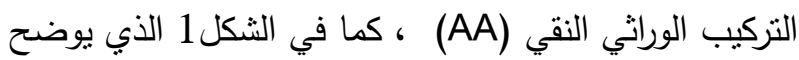
الحزم المتكونة في 11 أنموذج من عينات الأبقار المدروسة الحرية

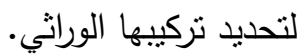

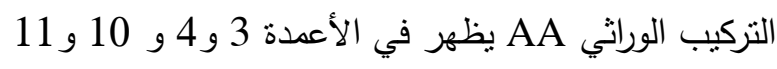

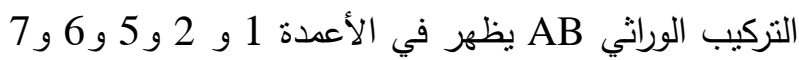
. 8 , توزيع التراكيب الوراثية لعينة اللاكتوفرين في عينة الأبقار المدروسة آتورية يتبين من الجدول 1 العدد والنسب المئوية للتراكيب الوراثية لجين اللاكتوفرين في العينة المدروسة ، اذ يظهر فروق عالية

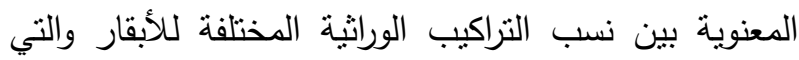

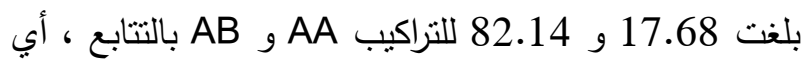
ان هناللك شيوعا واضحا للأفراد الهجينة ( AB) مع تدني نسبة التركيب الوراثي السائد (AA) وانعدام التركيب الوراثي المتحي (BB) في العينة . وهذا جاء منققا مع دراسة 
النوالي (جدول 4 ) أما Zielak-Steciwko وأخرون(19 ) وجدت ان إنتاج الحليب الكلي لأبقار الهولثناين الفريزيان الهولندية كان لصالح التركيب الوراثي AA ، بينما كانت النسب في دراسة Maletić (12 ) للتركيب الوراثي السائد (AA)

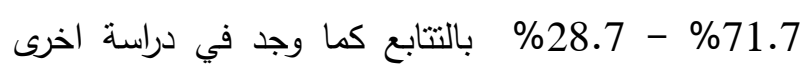
Asadollahpour السائد(AA) اكبر من التركيب الوراتي الهجين (AB) اذ (AB)

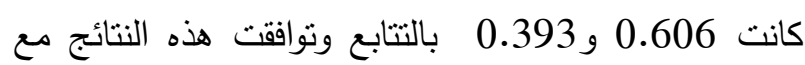

دراسة Pawlik (15) (15).
تأثير تعدد مظاهر جين اللاكتوفرين للأبقار في إنتاج الحليب

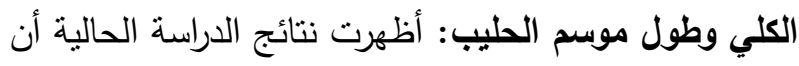
التباين في إنتاج الحليب الكلي وطول موسم الحليب باختلاف التركيب الوراثي لجين اللاكتوفرين معنويا ، أذ حققت الأبقار ذات التركيب الوراتي الهجين AB اقصى معدل إنتاج حليب كلي (2447,37 ـ 209,06 كغم) في حين بلغ معدل 120,14 1205,70) AA الإنتاج لدى التركيب الوراثي كغم)، أما (3 ) فوجدت ان إنتاج الحليب الكلي لأبقار

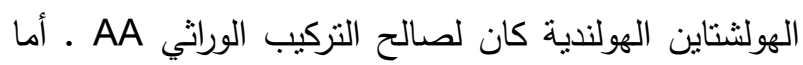
معدلات طول موسم الحليب فقد بلغ 182,00 ـ 3.83 و

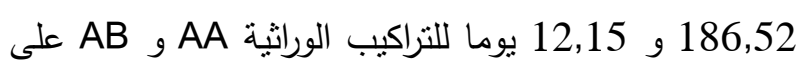
جدول 4 : تأثير تعدد مظاهر جين اللاكتوفرين في إنتاج الحليب الكلي وطول موسم الحليب (متوسط المريعات الصغرى \pm الخطأ القياسي)

\begin{tabular}{|c|c|c|c|}
\hline \multirow[b]{2}{*}{ مستوى المعنوية } & \multicolumn{2}{|c|}{ التركيب الوراثي (Genotype) } & \multirow[b]{2}{*}{ 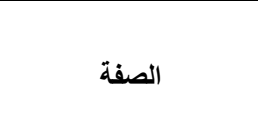 } \\
\hline & $\begin{array}{c}\text { AB } \\
\text { (23 العدد (العد) }\end{array}$ & $\begin{array}{c}\text { AA } \\
\text { (5 العدد (ا) }\end{array}$ & \\
\hline$* *$ & a $209.06 \pm 2447.37$ & b $120.14 \pm 1205.70$ & إنتاج الحليب الكلي (كفم) \\
\hline NS & $\begin{array}{l}\text { a } 12.15 \text { × } 186.52 \\
\text { تختلف معنويا فيما بينها. }\end{array}$ & $\begin{array}{c}\text { a } 3.83 \text { I } 182.00 \\
\text { التي تحمل حروف مختلة ر* *0.01 }\end{array}$ & طول موسم الحليب (يوم) \\
\hline
\end{tabular}

AB على التركيب الوراثي الهجين AA عيني النقي للجين

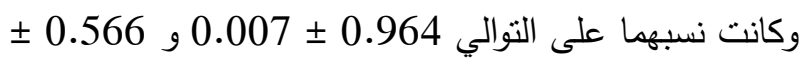
0.008 وكما حصل Ahmed (1) على النتيجة ذاتها في على نسبة الدهن لأبقار الهولشتاين وكانت النتيجة لصالح التركيب

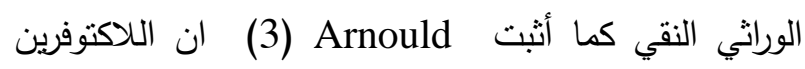
يرنبط عكسيا مع نسبة الدهن بينما وجدت فروق معنويه في

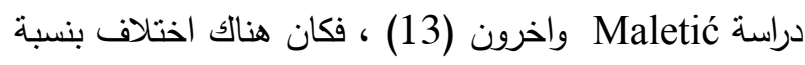
AA البروتين في الحليب اذ كان اعلى في التركيب الوراثي مقارنة بالتركيب AB A.29 - 3.22) على التوالي وأيضا بنفس الدراسة وجدت فورق في نسبة الدهن وكانت لصالح ألتركيب الوراثي AA وأيضا وجد ارتفاع بنسبة الدهن والبروتين ولصالح التركيب الوراثي النقي AA مقارنة بالهجين Zielak-Adrianna واخرون (19) اذ كان نسبة البروتين عالية

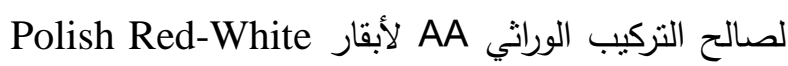
مقارنة بالتركيب الهجين (PRW) ان نسبة الدهن في الحليب كانت عالية في التركيب الوراثي الهجين AB مقارنة بالتركيب الوراثي النقي AA ولنفس في فئ

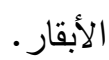

تأثثر تعدد مظاهر جين اللاكتوفرين للأبقار في مكونات الحليب: يتضح من الجدول 5 ان نسبة الدهن تأثرت معنويا باختلاف المظاهر المتعددة لجين اللاكتوفرين أذ بلغت لئت

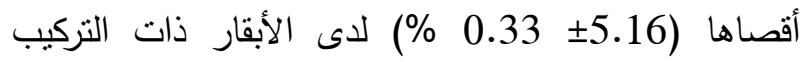

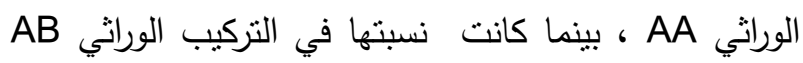

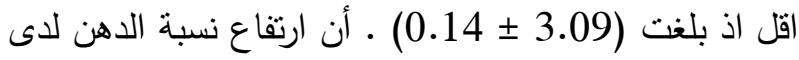
الأبقار ذات التركيب الوراثي النقي AA جاء متتاغما مع انخفاض معدل إنتاج الحليب الكلي لدى الأبقار من هذاء مناء التركيب الوراثي كما ذكر أنفا (الجدول5) ، اذ ان زيادة كمية

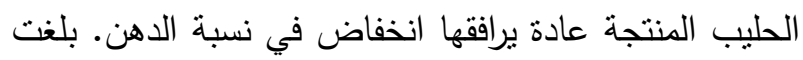

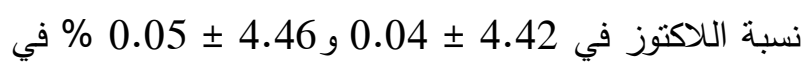
حليب الأبقار ذات التراكيب AA و AB بالتنابع، ولا نوجد فروق معنوية هنا. أما نسبة البروتين فلم تتأثز معنويا باختلاف المظاهر المتعددة لجين اللاكتوفرين فقد بلغت نسبها

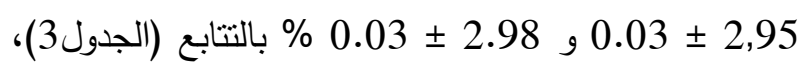
أن نسبة المواد الصلبة غير الدهنية لم نتأثز معنويا باختلاف التركيب الوراثي اذ كانت نسبتها 8.06 ـ 0.07 و 8.10 ـ 8.06 0.10 بالتتابع ، يتبين من الجدول5ان نسبة الرماد نأثرت معنويا باختلاف التركيب الوراثي للجين ،اذ تفوق التركيب 


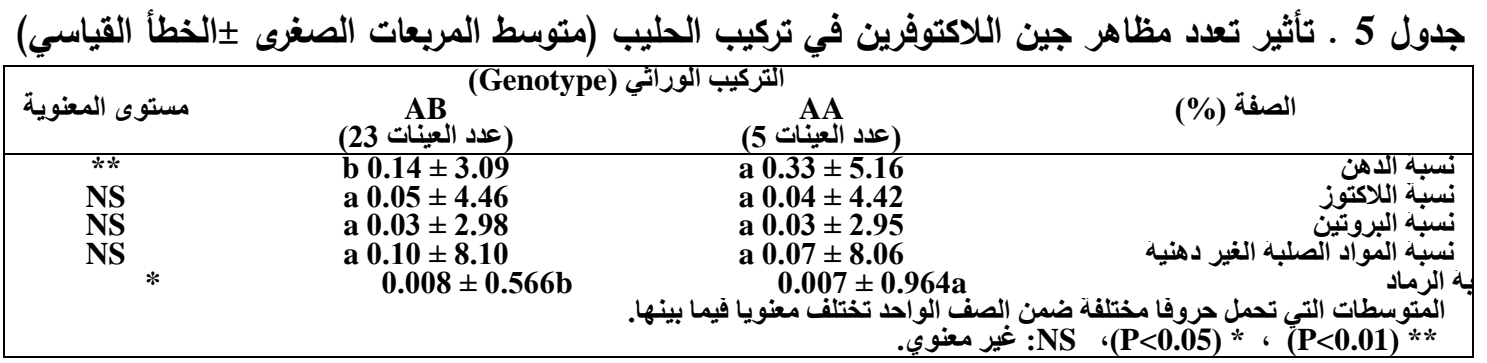

\section{REFERENCES}

1. Ahmed, J.R. 2015. Study of Genetic Polymorphism of Iron Transfer (Transferrin) and Hemoglob- in Type in Holsteincows for selection. M.Sc. Tesis. College of Agriculture.Universityof Baghdad.2,56-57. (in Arabic)

2. Alain, V. M. Dens, S. Magali, And. E. Andre. 2002.A review on SNP and other types of molecular markers and their use in animal genetics Genet. Sel. Vol. 34 .

3. Arnould, H., Soyeurt, N. Gengler, F. G. Colinet, M. V. Georges, C. Bertozzi,D. Portetelle, and R. Renaville. 2009. Genetic analysis of lactoferrin content in bovine milk, American Dairy Science Association, J. Dairy Sci. 92:2151-2158.

4.Pawlik,A., G. Sender, and A. KorwinKossakowska. 2014. Bovine lactoferrin gene polymorphism and expressionin relation to mastitis resistance. Animal Science Papers and Reports vol. $27:$ 4, 263-271

5.Asadollahpour Nanaei, H., S. Ansari Mahyari and M. A. Edriss , 2016. Single nucleotide polymorphism of the lactoferrin gene and its association with milk production and reproduction traits in Iranian Holstein cattle , Journal of Livestock Science and Technologies, 4 (1): 71-76. 6. Brock , J. H. 1980.Lactoferrin in human milk :Its role in iron absorption and protection against enteric infection in the newborn infant .Arch . Dis .Child.55:417.

7- Duncan D B., 1955. Multiple range and multiple F tests. Biometrics 11:1-42.

8- Green M.R., J.V., Pastewka , 1978. Lactoferrin is a marker for prolactin response in mouse mammary explants. Endocrinol-ogy 103, 1510-1513.

9- Igarashi, M.I.S.P., T.M. Machado, J.A. Ferro, and E.P.B. Contel, 2000. Structure and genetic relationship among Brazilian and imported goat breeds. Biochemical Genetics. 38: 353-365.

10- Liu, J. and J.F. Cordess, 2004 . DNA marker technology and their Applications in aquaculture genetics, Aquaculture238:1-37.

11.Masson, P. L. and J. F. Heremans, 1971. Lactoferrin in Milk from Different species . Comparative Biochemistry and Phsiology, 39B: 119-129.

12. Maletić. M., Va kanjac slobodanka, djelić n, lakić nada, pavlović m, nedić svetlana and stanimirović $\mathrm{z}, 2013$. ANALYSIS OF lactoferrin gene polymo phism and its association tomilk quality and mammary gland healt $h$ in holstein-friesian cows, acta veterinaria (beograd), 63, 5-6: 487-498.

13. Montaldo, H.H. and C.A. Meza-Herrera, 1997. Use of molecular markers and major genes in the genetic improvement of Livestock. EJB Electronic Journal of Biotechnology 1(2):84-91 .

14. Nottenburg, C. and J. Shnqrples, 2004. Analysis of "junkDNA" patents.cambia and carol Nottenburg , Canberra ACT. Autralia, $\mathrm{P}: 1-20$.

15. Pawlik, A., G. Sender,and A. KorwinKosakowska, 2009. Bovi- ne lactoferrin gene polymorphism and expression in relation to mastitis resistance-review, Anim Sci Pat Rep,27, 263-71.

16. Rafay, J. 2001. Hybridization of broiler rabbit breeding: Habilitacna, Nitra: Spu.,255. 17. Sharifzadeh,A.andA.Doosti. 2011. Study of lactoferrin gene polymorphism in iranian holstein cattle using PCR-RFLP Technique, GloblalVeterinaria 6(6): 530-536.

18. Williams, J.L. 2005. The use of markerassisted selection in animal breeding and biotechnology. Rev. Sci. Tech. off. Int. epiz.1(1):24

19. Zielak-Steciwko, A, E. EwaPecka. Marzena Kesek. Marian Kuczaj. Tadeusz Szuk. 2014. Changes in the proportion of proteins fractions depending On lactoferrinpol-ymorphism gene and the somatic cells count in the milk of polish Holsteinfrisian and polish red-white cattle, veternarijair zootechnika (Vet Med Zoot). T.66(88). 